\title{
Lexical Accuracy and Reaction Time in Second Language Reading Proficiency in Indonesia
}

\author{
Sahiruddin \\ Universitas Brawijaya \\ \{shrdn@ub.ac.id\}
}

\begin{abstract}
This article examines the degree to which lexical performance as reflected in accuracy and response time contributes to the $\mathrm{L} 2$ reading proficiency. The use of response time as proficiency indicator has been much neglected in L2 reading research. This study argues that lexical response time and lexical accuracy can mirror the development of L2 reading proficiency. One hundred and forty one university students $(n=141)$ in Indonesia voluntarily participated in this study. Online time-yes/no test was used as a measure lexical performance and reading test was to assess L2 reading proficiency. This study revealed that performance for both lexical accuracy and response time significantly predict $\mathrm{L} 2$ reading proficiency, indicating that response time as elicited from online time-based testing can be taken into account as one of the L2 proficiency indexs to examine L2 development. Theoretical and practical implication of this study are discussed.
\end{abstract}

Keywords: Lexical Accuracy, Reaction/Response Time, L2 Reading Proficiency

\section{INTRODUCTION}

The ability to recognize words and their meaning (known as word recognition as an index of lexical performance) during reading has been widely acknowledged to play significant contribution in reading comprehension in first language setting [1]. It is the first lower level processing the readers should cope with when reading texts. Theoretically, word recognition is a bottleneck or building block in constructing the meaning of texts and latter largely affect reading comprehension [2]. In other words, inability to recognize words and their meaning in a text reading will certainly avoid readers to understand the meaning at word level, phrase level, sentence level and discourse level which overall hamper reading comprehension. Inefficient word recognition is a result of limited reading practice which in turn lead to restricted conceptual growth for individual and eventually continues to poor comprehension [3].

Theoretically, the role of word level knowledge in reading comprehension can be explained from verbal efficiency reading model [4] and the construction-integration reading model [5]. These theories have the same assumption about the role of word level knowledge on reading comprehension that word recognition is the first and basic lower level processing in reading to efficiently and effectively execute the meaning of texts. Although word level knowledge has been argued in terms of word recognition accuracy [6], [7].posits that word level speed processing in reading should be automatic to function 
well in reading comprehension. The automaticity in word recognition is critical in reading to engage in multiple or parallel processes in reading.

Word recognition itself is a representation of the learner's word knowledge or vocabulary in terms of the number of vocabulary they have (vocabulary size or breadth) and the efficient access to word meaning (vocabulary speed or fluency). This study used these two variables (size and speed) to define word knowledge construct. The construct of lexical facility was introduced by Harrington [8] to explain the two dimensions of vocabulary, in terms of vocabulary size and speed processing, and this construct motivated this study. It is argued that word level processing in reading should be automatic, and certain lexical threshold should be met to function well in reading comprehension. The automaticity in word recognition is critical in reading to engage in multiple or parallel processes in reading. From psychometric perspective, word recognition as assessed by lexical decision task, vocabulary level test (vocabulary size test) or the Yes/No test, and vocabulary speed as assessed from response time (RT) when doing the item test or eye-movement/eye-tracking studies are highly correlated and the most robust predictor of reading comprehension as measured by reading accuracy and reading comprehension in L1 setting either in children [9] and adult native readers [10]. Dealing with vocabulary breadth, certain lexical threshold is required to do certain tasks in L2 condition. It is argued that 8000-9000 word families and 98\% lexical coverage is prerequisite for written text comprehension and 6000-7000 word for spoken text [11]. Recently, it was proposed that $98-99 \%$ lexical coverage is required for independent reading text for comprehension [12].These above studies seem to suggest the role of lexical knowledge in text comprehension and generally $98-99 \%$ are largely agreed to be prerequisite of lexical coverage for comprehension. In other words, comprehension increases as lexical size increase. However, lexical size level in relation to text comprehension is still mixed and in need of further study.

In L2 setting, the role of word recognition on L2 reading comprehension has been theoretically more important in terms of cross-linguistic processing and word recognition essentially refers to as a bottleneck of reading comprehension [13]. However, L2 reading studies showed partial supports about the role of word recognition on reading performance. For some contexts, word level knowledge as measured from vocabulary size and speed perspective was found correlated and predicting L2 reading. For instance, recent meta-analysis of 59 reading studies in L2 reading by reading scholars [14] reveals that word level skills are the most influential factors in L2 reading proficiency $(r=.79)$. In contrast, L2 studies also found zero to moderate correlation with L2 reading. In adult L2 context, low correlation was evident in investigating L2 university learners in Taiwan demonstrating that vocabulary gap-filling was correlated with reading test at $r .37$ [15]. Similar value was found in [16] suggesting of $r .35$ for $3 \mathrm{~K}$ vocabulary level test and reading comprehension test. It was also found that word knowledge (as measured via lexical decision task) did not correlate to reading comprehension at r.04 [17]. Similarly, ESL Japanese university learners were also observed in the absence of correlation between word identification as assessed by sight word reading as to judge an item a real word or not (words and pseudowords) and reading comprehension ( $r=.-13)$ [18]. It may be that low correlation between word recognition and L2 reading is due to the fact that word identification test and reading test were too difficult for learners. In vocabulary speed studies, word knowledge as assessed from word recognition speed was reported to have high correlation to reading comprehension test (National reading high school 
examination) $r=-.47$, signifying that better comprehension is related to faster reaction times or lexical processing speed [19].

These mixed results demonstrated that more research is needed to explore these issues. One of the interests of the present study was to examine whether the role of word knowledge (vocabulary size and speed) affects L2 reading proficiency. The hypothesis would be that word acuracy and response time will bring contribution for L2 learners, particularly in an Indonesian context.

In Indonesian EFL setting, English is the first main foreign language taught as compulsory subject in school since Indonesia's independence in 1945 [20]. Since English became an international language at that time, Indonesian government recognized that by learning this language, student can access intellectual and the artistic wealth of the world. English has been taught from secondary school to tertiary level although some schools include English subject at primary school as local choice. Reading has been one of the salient missions of English language teaching and learning in EFL context, particularly the ability to read and learn from English textbooks or references [21]. However, reading comprehension has been a challenging skill in L2 contexts. It has been evident that although reading comprehension has always become the focus in English curriculum in Indonesia, Indonesia still suffers from a low reading and low reading performance in Indonesian university students [17]. There are several factors which contribute to the low reading skills in Indonesian education context such as lack of word level knowledge, inadequate of topic familiarity and linguistic problem [22]. Of such factors, it was argued here that word level knowledge was the most determinant factors making Indonesian learners having low reading ability.

The fact that reading performance in Indonesia was still low might be because reading instruction focused more on higher level processing in reading while learners were not equipped with word level knowledge (having inadequate word level knowledge) so that this reading method seems unsuccessful in developing L2 reading in Indonesia. In this point, this study assesses whether word knowledge as assessed from lexical accuracy (breadth) and lexical response time (speed) did really predict reading comprehension in Indonesia and consequently proposes that language teaching emphasizing on vocabularydevelopment should be put in priority in L2 reading development in Indonesia.

This study is important for a number of reasons. At the level of theory, the results may contribute insights or better understanding of how lower level processes in reading (word level knowledge) contribute to higher level comprehension processes in Indonesian EFL context. The findings of the study could potentially provide support or feedback for Perfetti's [23] theories of verbal efficiency, and theory of construction-integration model in reading process. On the educational policy making, this study might provide valuable information for English curriculum developers, English reading teachers, or material developers of how L2 reading should be perceived and processed by Indonesian learners. In short, this study examine the degree to which lexical accuracy and response time predict $\mathrm{L} 2$ reading proficiency.

\subsection{Research Method}

This study is quantitative in nature as it scrutinizes the effect of word level knowledge on L2 reading through testing instrument [24]. One hundred and forty one participants $(n=141)$ were voluntarily registered in this study. They were Indonesian EFL students enrolled in an Indonesian university English Study Program. Word knowledge 
was assessed in terms of receptive lexical decision task using Online Timed Yes/No test [25], a computer-based test consists of a mix of word and non-word prompts presented individually. The learner simply indicates via a keystroke whether the presented item is known. Word items are sampled from a range of frequency of occurrence bands $(2 \mathrm{~K}, 3 \mathrm{~K}$, $5 \mathrm{~K}$, and $10 \mathrm{~K}$ ) and including words occurring with very high frequency to those occurring far less commonly. The nonword items consist of phonologically possible words in generated by substituting or exchanging 1-2 letters of existing words and screened by native readers for English readability. The vocabulary level test version consists of 100 items comprised of 72 words and 28 non-words. The 72 words consist of 18 words each at four levels of frequency of occurrence. Meanwhile, wordlist test containing of words taken from the tested passages consisted of 50 words and 15 nonwords. Order of item presentation in the list was randomized. The words were obtained from words lists drawn from the British National Corpus published on the LexTutorwebsite, www.lextutor.com.ca. Performance was measured by item accuracy and speed of response time (RT). Accuracy was measured by the number of word items correctly identified minus the number of nonwords incorrectly identified, thus providing a means to correct the score for guessing [26]. Reaction time or response time (RT) for individual items was measured from the time the item appeared on the screen until the student initiated the key press. Each item remained on the screen for 5 seconds (5000 milliseconds), after which it was timed out if there is no response. Timed out responses were treated as incorrect. The accuracy response alternatives in the the Yes/No test are understood as in previous studies. 'Yes' responses to real words (hits) reflect the individual's vocabulary knowledge, while the rate of 'Yes' responses to pseudowords (false alarms) measures the individual's tendency to guess as what they thought that the pseudowords to be the real words in English. Although both hits and the correct rejections of non-words are correct responses, the number of hits, adjusted by the false alarm rate, is of primary interest.This study used the $c f g$ scoring method which has been used in many studies [27]. The corrected scores were calculated by subtracting the false alarm $(F A)$ from the hits

Reading comprehension was assessed using material adapted from the reading sections of published TOEFL tests [28]. Reading comprehension tests were projected through online computerized test (online reading). Participants were provided with computer where each of them read the four passages with the constraint that once they read the passages and clicked the next or question buttons, they cannot get back to previous screen or previous text. Since the readers cannot go back to previous screen, it involves memory attention in answering the tasks so that the comprehension questions were only limited to five multiple-choice questions, for instance, excluding questions about vocabulary. This passage reading tasks took place in one session lasted approximately 60 minutes. Overall, participants completed four reading tasks and they were required to answer each set of questions based on memory of what had been read, without the opportunity to look back at the text.

Test scores for the Yes/No test were calculated for hits at each level (2000, 3000, 5000 , and 10000) and for an overall corrected score. The corrected score was calculated by subtracting the false alarm rate from the hits rate for each individual. Reliability estimates were calculated from both the Yes/No test and the reading test. Descriptive statistics for the test accuracy and reaction time data results for the word knowledge and reading test are presented. Then, the correlation analysis was conducted to see the effect of word knowledge and reading performance, and regression analysis was calculated to 
predict participants' reading performance based upon their word level knowledge, and reading performance.

\section{RESULT AND DISCUSSION}

The reliability of the Yes/No lists was calculated using Cronbach's alpha, a measure of internal consistency.Overall reliability for the Yes/No test accuracy was .84. In addition, reliability for the word and nonword itemswas calculated separately, as the two sets are assumed to represent different dimensions of knowledge [29]. For the word results the coefficient estimate was .89 for Vocabulary Level Test while pseudoword performance was .79 respectively. Reliability coefficients of $.8-.9$ are considered strong, so the overall word knowledge tests here showed strong reliability [30]. Meanwhile, the reliability of reading performance had a Cronbach's alpha coefficient of .84. The normality of data set in this study was assessed using skewness and kurtosis principle test. All data displayed normal distribution within the ranges of normal kurtosis and skewness as the values were not greater than 1.96 or 2.58 [24]. Since word knowledge word knowledge were measured through the Yes/No test, the normality of those data accounted for both accuracy and response time was calculated. The accuracy data were all normally distributed; the Yes/No test with skewness of $-0.12(S E=0.20)$ and kurtosis of $-0.46(S E=0.40)$. For the Yes/No test response time also revealed normal distributions; the Yes/No test with skewness of $0.82(S E=0.20)$ and kurtosis of $0.50 \quad(S E=0.40)$. Meanwhile, the reading tests containing eight texts were presented for each participant. The reading data were within the range of normality, with skewness of $0.18 \& 0.54$ $(S E=0.28)$ and kurtosis of $0.36 \&-0.29 \quad(S E=0.56)$. The data were all normally distributed as assessed through the value of skewness and kurtosis based on the idea that the data was normally distributed since the values were not greater than 1.96 or 2.58 .

The main focus of this study was to examine the relationships between independent variables (word knowledge accuracy and response time) and dependent variable (reading comprehension). Table 1 presents overall accuracy performance and by frequency levels $(2000,3000,5000,10,000)$ for Vocabulary Level test / the Yes/No test. It reported mean and standard deviation for hits (proportion of 'yes' responses to words), the false alarm rate (proportion of 'yes' responses to pesudowords), and corrected scores for the whole group. Overall mean accuracy (corrected for guessing) for the Yes/ No test was about $67 \%(M=67, S D=11)$. The performance approached ceiling for the 2000-3000 level at $78 \%-98 \%$. Students' performance declined below $70 \%$ at the 5000 level and sharply fell off to $30 \%$ at the 10,000 levels. It has been argued in terms of lexical threshold and reading theory that readers were required to have 8000-9000 word level to enable them to read English texts (Nation, 2006, Schmitt et al, 2011). Referring to this point, students' word knowledge in this study was below the expected threshold to be able to read English text.

Table 1: The Yes/No accuracy scores by frequency levels for Hits, False Alarms, and Corrected Scores $(n=141)$.

\begin{tabular}{lll}
\hline Frequency levels & Vocabulary level test scores & \\
& M & SD \\
\hline 2000 & 98 & 4.0 \\
3000 & 78 & 16.6 \\
5000 & 67 & 17.2
\end{tabular}




\begin{tabular}{lll}
\hline 10,000 & 30 & 17.1 \\
False Alarm & 19 & 11.8 \\
Hits & 67 & 11.8 \\
Corrected score & 66 & 11.4 \\
\hline
\end{tabular}

Overall, the study shows that the participants have limited vocabulary especially at the level of $5 \mathrm{~K}$ and $10 \mathrm{~K}$ word frequency levels in the test. This suggests that language teachers need to give more attention to developing the needed vocabulary knowledge, either in receptive knowledge or productive knowledge of vocabulary. It has been argued that the more vocabulary knowledge the learners have, the more they can deal with the language, especially to cope with language skills, such as reading, writing, listening, and speaking.

The use of Yes/No format may also be used to develop a better sensitivity to the orthographic and phonological patterns of L2 lexis on the part of the learners. The use of the task for training could facilitate the automatization of lexical processes, especially retrieval. It may also be used for spoken and text comprehension tasks, e.g., as a diagnostic pre-reading test in which the learner's knowledge of vocabulary in a target text is assessed.

In a global context of performance, the Yes/No must be interpreted within a larger theoretical framework that specifies the role of word recognition in L2 processing and development [31]. Word recognition plays an important role especially in level of L2 sentence processing. It is also assumed here that this word recognition or lexical access performance also relates further global comprehension processes, especially in reading comprehension. In more practical terms, how response accuracy could be the predictive power of global reading comprehension still needs to be addressed.

Table 2: The Yes/No response times (RT) by frequency levels ( $\mathrm{n}=141)$.

\begin{tabular}{lll}
\hline Frequency levels & Vocabulary level test RT (msec) & \\
& M & SD \\
\hline 2000 & 896 & 154 \\
3000 & 1002 & 150 \\
5000 & 1099 & 211 \\
10,000 & 1255 & 337 \\
Overall & 1064 & 184 \\
\hline
\end{tabular}

The reaction time or response time (RT) data are based on correct responses to words. As word items were timed out after $3000 \mathrm{~ms}$, individual response times were not screened for outliers. A $\log$ transformation was performed on the raw response times prior to statistical analysis. The interpretation of reaction times performance is dependent upon the evidence of trade-offs in speed and accuracy by individuals. The existence of speed-accuracy trade-offs (high accuracy - slow response time) indicates that RT is less a measure of lexical proficiency. The descriptive statistics for the reaction time measures for word correct responses are given in Table 2. Reaction times by some word knowledge tests were ranged from 896 to $955 \mathrm{msec}$ at the $2 \mathrm{~K}$ level (most easy and familiar words) to 1250 to $1263 \mathrm{msec}$ at the $10 \mathrm{~K}$ level. There was also more variability at the $5 \mathrm{~K}$ and $10 \mathrm{~K}$ levels, as reflected in larger standard deviations.

The interpretation of reaction time in relation to accuracy data can be potentially understood from speed-accuracy trade-offs. Trade-offs occurs when there was high positive correlation between accuracy scores and reactions times, reflection high 
accuracy scores with large or slow reaction time; low accuracy scores occurring with low RTs [25]. There was a significant negative correlation between accuracy scores and mean RT, $r=-.484$, significant at $p<.001$. This suggests that there was no evidence for a systematic trade-offs in speed-accuracy in this study, indicating that response time data can be considered as good measure of lexical proficiency. Negative correlation between accuracy and response time indicates that the participants maximize their vocabulary knowledge performance; no trade-offs performance.

The study reveals that the overall mean accuracy for reading was about $42(\mathrm{SD}=15.7)$, indicating that the reading test was too challenging for this this context where a number of test received very low scores. In addition, reading performance may have been affected by vocabulary limitations. As above mentioned in the Yes/No test section report, the learners in this study knew as little vocabulary as half of the vocabulary at the 5,000 word level and only $30 \%$ of the vocabulary at the 10,000 word levels. This may have limited their ability to do the reading texts. Specifically, a vocabulary of $8,000-9,000$ word families is required for $98 \%$ text coverage, which in turn is needed for adequate text comprehension [11]. Since the learners in this study possessed limited vocabulary knowledge, they were considered inadequate readers.

A potential association between Yes/No test and overall reading scores was tested by performing a Pearson product moment correlation. The results show significant moderate correlation between reading scores and vocabulary measures (accuracy and response time), ranged from $r=.59$ for accuracy and -.33 for response times. Accuracy scores indicated a slightly higher correlation than response time data. As an independent measure, response time proved to be less sensitive to reading performance as the criterion variable. Thus, there was evidence of relationship between vocabulary performance and reading performance for the individuals in this study.

These accuracy values were similar to the ones reported previous studies, such as [32] with .50, and [33] with .59. In contrast, the accuracy values were lower than other previous studies, such as [14] with .79, [34] with .80, and [35] with .74. On the other sides, the values reported here was higher than the one reported in [16] with .35, [15] with .37, [17] with .04, [18] with -.13.

In regards to the relation of word knowledge response time (lexical processing speed) to reading performance in this study, it has been acknowledged that not many studies examined the role of word knowledge in L2 reading comprehension so that not many studies could be compared to this study. One of the studies examining this issue was [19] who found the inverse correlation of word processing speed and reading comprehension in Netherland with -.47 in which the value reported was slightly higher than that of this study. Harrington and Roche (2014) revealed a negative correlation of -.15 and -.26 for 174 Omani students. These values were lower than the ones reported in this study. In addition, it was also reported that word knowledge speed was moderately correlated with L2 reading performance (correlation value not reported) and yet it did not provide a unique variance in L2 reading comprehension

Since the all assumptions were met, hierarchical multiple regression was conducted with reading comprehension as dependent variables. The Yes/No test accuracy scores was entered at the stage one of regression, and response time was entered at stage two. The intercorrelations between the multiple regression variables were reported in Table 3. 
Table 3 Summary of Hierarchical regression analysis for variables predicting reading performance.

\begin{tabular}{|c|c|c|c|c|c|c|}
\hline Combined vocabulary model & $R^{2}$ & $\begin{array}{l}\text { Change in } \\
R^{2}\end{array}$ & $F$ change & Sig $F$ change & SEB & $\beta$ \\
\hline $\begin{array}{l}\text { Step 1 } \\
\text { Accuracy }\end{array}$ & .351 & .346 & 75.31 & .000 & .000 & .592 \\
\hline $\begin{array}{l}\text { STEP } 2 \\
\text { Response time }\end{array}$ & .375 & .366 & 5.32 & .000 & .023 & .537 \\
\hline
\end{tabular}

SEB, Standard Error of unstandardized coefficient; $\beta$, standardized coefficient.

The predictive power of Yes/No test accuracy and response times was overall $37 \%$ variance of reading comprehension. The beta values were all statistically significant. As explained by the model indicated that both accuracy and response time all serve to some degree to reliably discriminate between individual differences in reading performance. Accuracy accounted for $34 \%$ of reading variance, and response time explained $2 \%$ of reading outcome. The study showed that contribution of lexical response time lags behind lexical accuracy. This information provide other L2 reading researchers with a direct indication of how word knowledge could measure and classify L2 reading performance. This predictive capacity value was similar to [36] with $36 \%$. This value was lower than [35] with $54 \%$ of reading variance, [32] with $56 \%$ from $3 \mathrm{~K}$ VLT, and [34] with $64 \%$. Although lexical accuracy demonstrates a better prediction for L2 reading proficiency, lexical response time as an index of lexical processing speed significantly contribute to the variation of $\mathrm{L} 2$ reading performance. In addition, the use of online test for measuring processing speed in word recognition can potentially be used for placement purposes in L2 setting. This finally support the notion of lexical facility construct and its role in L2 proficiency by Harrington [8], and also support the importance of lower level processes in reading comprehension processes by verbal efficiency theory [4] and contructionintegration model [5].

\section{CONCLUSIONS}

This study investigated the effect of lexical accuracy and response time (processing speed) in explaining the variation in second-language reading outcomes among Indonesian learners of English as a foreign language (EFL). There are several points that can be drawn from the findings of this study. First, higher vocabulary students showed faster processing skill in recognising words when compared to lower vocabulary students. Second, vocabulary size knowledge demonstrated a more significant contribution than lexical processing speed in explaining L2 reading variance. Third, it is evident that the strength of the effect of vocabulary size varied from high lexical frequency to low lexical frequency texts. This ultimately supports the importance of lower-level processing skills in $\mathrm{L} 2$ reading comprehension.

\section{REFERENCES}

[1] Adams, M. J. (1990). Beginning to read: Thinking and learning about print. Cambridg, MA: MIT Press.

[2] Grabe, W. (2009). Reading in a second language: Moving from theory to practice. New York: Cambridge University Press. 
[3] Koda, K. (2005). Insights into Second Language Reading: A cross-linguistic approach. New Yrok: Cambridge University Press.

[4] Perfetti, C. A. (1985). Reading ability. New York: Oxford University Press.

[5] Kintsch, W. (2005). Comprehension. Mahwah, NJ: Erlbaum.

[6] Nassaji, H. (2014). The role and importance of lower-level processes in second language reading. Language Teaching 47(1), 1-37. doi: $10.1017 / \mathrm{S} 0261444813000396$

[7] galowitz, N. (2010). Cognitive bases of second language fluency. New York, NY: Routledge.

[8] Harrington, M. (2018). Lexical facility: size, recognition speed and consistency as dimensions of second language vocabulary knowledge. United Kingdom: Palgrave Micmillan.

[9] Carver, R. P. (2000). The causes of high and low reading achievement. Mahwah, NJ: Lawrence Erlbaum.

[10] Bell, L. C., \& Perfetti, C. A. (1994). Reading Skill: Some Adult Comparisons. Journal of Educational Psychology, 86(2), 244-255.

[11] Nation, P. (2006). How Large a Vocabulary Is Needed For Reading and Listening? The Canadian Modern Language Review, 63(1), 59-82.

[12] Schmitt, N., Jiang, X., \& Grabe, W. (2011). The Percentage of Words Known in a Text and Reading Comprehension. The Modern Language Journal, 95(i), 26-43. doi: 10.1111/j.1540-4781.2011.01146.x

[13] Grabe, W. (2009). Reading in a second language: Moving from theory to practice. New York: Cambridge University Press.

[14] Jeon, E. H., \& Yamashita, J. (2014). L2 Reading Comprehension and Its Correlates: A Meta-Analysis. Language Learning, 64(1), 160-212. doi: 10.1111/lang.12034

[15] Haynes, M., \& Carr, T. H. (1990). Writing system background and second language reading: A component skills analysis of English reading by na tive speaking-readers of Chinese. In T. H. Carr \& B. A. Levy (Eds.), Reading and its development: Component skills approach (pp. 375-421). San Diego, CA: Academic Press.

[16] Al-Nujaidi, A. H. (2003). The Relationship Between Vocabulary Size, Reading Strategies, and Reading Comprehension of EFL Learners in Saudi Arabia. (Doctor of Philosophy), Oklahama State University. (3094023)

[17] Sahiruddin. (2008). Examining The Relationship between Performance in The Yes/No Test and Reading Skills. Journal of Indonesian Islam, 2(2), 379-403.

[18] Yamashita, J. (2013). Word recognition subcomponents and passage level reading in a foreign language. Reading in a Foreign Language, 25(1), 52-71.

[19] Gelderen, A. v., Schoonen, R., Stoel, R. D., Glopper, K. d., \& Hulstijn, J. (2007). Development of Adolescent Reading Comprehension in Language 1 and Language 2: A Longitudinal Analysis of Constituent Components. Journal of Educational Psychology, 99(3), 477-491. doi: 10.1037/0022-0663.99.3.477

[20] Dardjowidjojo, S. (2003). Rampai bahasa, pendidikan, dan budaya (Language, education, and culture). Jakarta: Yayasan Obor Indonesia.

[21] Richards, J. C., \& Renandya, W. A. (2002). Methodology in Language Teaching: An Anthology of Current Practice. USA: Cambridge University Press.

[22] Kweldju, S. (1996). English department students interest and strategies in reading their content area textbooks. TEFLIN Journal, 8(1), 104-117. 
[23] Perfetti, C. A. (1988). Verbal efficiency in reading ability. In G. E. MacKinnon, T. Waller \& M. Daneman (Eds.), Reading research: Advances in theory and practice (Vol. 6). New York: Academic.

[24] Field, A. (2013). Discovering Statistics using SPSS (Third ed.). Thousand Oaks, California: SAGE Publications Inc.

[25] Harrington, M. (2006). The lexical decision task as a measure of L2 lexical proficiency. EUROSLA Yearbook, 6, 47-68.

[26] Sanchez, A. P., \& Schmitt, N. (2012). Scoring Yes-No vocabulary tests: Reaction time vs. nonword approaches. Language Testing, $0,1-21$. doi: $10.1177 / 0265532212438053$

[27] Mochida, A., \& Harrington, M. (2006). The Yes/No test as a measure of receptive vocabulary knowledge. Language Testing 23(1), 73-98. doi: 10.1191/02655322061t321oa

[28] Duffy, C. B., \& Mahnke, M. K. (1998). The Heinemann ELT TOEFL Practice Test. New York: Macmillan Publishers Limited.

[29] Harrington, M., \& Carey, M. (2009). The on-line Yes/No test as a placement tool. System, 37, 614-626.

[30] Brown, J. D. (1990). Testing in Language Programs. Upper Saddle River, NJ: Prentice Hall.

[31] Koda, K. (1996). L2 word recognition research: A critical review. The Modern Language Journal, 80(4), 450-460.

[32] Laufer, B. (1992). How much lexis is necessary for reading comprehension? In H. B. P. Arnaud (Ed.), Vocabulary and applied linguistics (pp. 126-132). London: MacMillan.

[33] Nassaji, H. (2003). Higher-Level and Lower-Level Text Processing Skills in Advanced ESL Reading Comprehension. The Modern Language Journal, 2, 261276.

[34] Laufer, B., \& Ravenhorst-Kalovski, G. C. (2010). Lexical threshold revisited: Lexical text coverage, learners' vocabulary size and reading comprehension. Reading in a Foreign Language, 22(1), 15-30.

[35] Qian, D. (2002). Investigating the Relationship Between Vocabulary Knowledge and Academic Reading Performance: An Assessment Perspective. Language Learning, 52(3), 513-536.

[36] Shiotsu, T., \& Weir, C. J. (2007). The relative significance of syntactic knowledge and vocabulary breadth in the prediction of reading comprehension test performance. Language Testing,, 24(1), 99-128. doi: 10.1177/0265532207071513 